\title{
CONTATOS E DESACATOS: OS LÍNGUAS NA FRONTEIRA ENTRE SOCIEDADE COLONIZADORA E INDÍGENAS (1740 A 1889) - GOIÁS
}

THIAGO CANCELIER DIAS ${ }^{1}$

$U F G$

\begin{abstract}
RESUMO: Discute-se uma função de poder atribuído a indígenas conhecidos pela designação de "línguas" nos documentos históricos. Esses faziam a interlocução entre a sociedade colonizadora e as comunidades indígenas nos descimentos, aldeamentos e fortalezas. $E$ apresentado o processo histórico de formação dos mesmos a partir do estudo dos aldeamentos e colégios fundados em Goiás, para compreender quais eram as possibilidades de atuação, como foram representados e quais eram os possíveis espaços ocupados por esses agentes sociais bilíngues.
\end{abstract}

PALAVRAS-CHAVE: Intérpretes indígenas; colonização linguística; história indígena; história de Goiás.

ABSTRACT: It is discussed a function of power assigned to those indigenous known as "linguas" in historical documents. They were responsible for the communication between the colonizer society and the indigenous communities in situations where persuasion and influence were necessary. The historical process of formation of these historical subjects is shown from studies on the constitution of the indigenous and Portuguese/Brazilian borders.

KEYWORDS: Indigenous interpreters; linguistic colonization; indigenous history; Goiás history.

Sabe-se que a história sobre a relação entre indígenas e não indígenas em Goiás era de contatos, cooperações e conflitos. Com a descoberta do ouro em 1722, milhares de não indígenas invadiram territórios indígenas em busca de riquezas, terras e mão de obra. Com a expansão da fronteira colonizadora, as diversas etnias compartilharam

\footnotetext{
${ }^{1}$ Possui graduação em História (2006) e mestrado em História Cultural (2008) pela UFSC, com dissertação Questão Religiosa Catarinense: as disputas pelo direito de instruir (1843-1864). Doutorando em história pela UFG com pesquisa sobre as relações entre a sociedade colonizadora e nações indígenas em Goiás colonial. E-mail: cancelier@ hotmail.com .
}

Espaço Ameríndio, Porto Alegre, v. 7, n. 2, p. 205-226, jul./dez. 2013. 
THIAGO CANCELIER DIAS - Contatos e desacatos...

doenças trazidas pelos colonizadores, território menor e recursos naturais mais escassos, ampliando o conflito entre elas. Nesse cenário adverso, diversos homens e mulheres indígenas cumpriram função de mediadores se constituindo e sendo constituídos interlocutores privilegiados no contato com os não indígenas e provavelmente nas inter-relações entre as nações indígenas. A interlocução ocorria por intermédio do conhecimento de línguas indígenas e português. Tem-se a hipótese de que esse papel era negociado entre colonizadores e indígenas, e geralmente ocupado por indígenas chamados de línguas.

Algumas construções do saber histórico tendem a considerar o comportamento indígena como estanque e previsível; uma visão de realidade limitada à percepção construída a partir da leitura de documentos que expressam uma interpretação unilateral, formulada a partir do estudo da sociedade colonizadora sobre as comunidades indígenas (MONTEIRO, 1999, p. 240). A história indígena contada com o nativo sempre sofrendo a ação, como alguém que apenas reage às mudanças, como uma "somatória de externalidades: frentes de expansão, fricções interétnicas, políticas indígenas e indigenistas, ações da sociedade nacional e reações nativas" (SÁEZ, 2005, p. 39). Nessa perspectiva histórica, os indígenas são pensados principalmente a partir dos seus constituintes não indígenas, de tal maneira que são percebidos somente como objeto de diferentes políticas e de disputas entre agentes coloniais. Dessa maneira, os sujeitos indígenas têm seus comportamentos padronizados, esvaziados como pessoas atuantes e proponentes diante do mundo. Nessa perspectiva, pode se recorrer ao erro de esvaziar o sujeito como indivíduo político, controverso e atuante (MONTEIRO, 1999, p. 240).

Pensa-se o indígena como sujeito capaz de agenciar sua vida a partir de interesses e experiências próprias, da negociação com o outro, a partir de uma cultura dinâmica e por campos de atuação social permeadas de escolhas possíveis dentro dos processos históricos que perpassam a vida. Pensa-se como sujeitos que, apesar das adversidades, com as limitações de seu tempo, espaço e condição social, sempre agenciaram suas vidas, elaboraram estratégias a partir de interesses próprios, possuíram experiências significativas, foram atuantes e proponentes de mudanças e permanências. O estudo dos

Espaço Ameríndio, Porto Alegre, v. 7, n. 2, p. 205-226, jul./dez. 2013. 
THIAGO CANCELIER DIAS - Contatos e desacatos...

línguas parte de pressupostos divergentes daqueles arraigados na historiografia tradicional sobre a relação de contato entre indígenas e colonizadores, pensada essa a partir do binômio que opõe um tipo de indígena resistente e aguerrido e outro colaborador (MONTEIRO, 1999, p. 239). Concorda-se com Maria Almeida quando afirma que

Sem desconsiderar a violência e a opressão da conquista, é possível perceber que as atitudes dos índios em relação aos colonizadores não se reduziram, absolutamente, à resistência armada e à submissão passiva. Houve diversas formas do que se pode chamar de resistência adaptativa, através das quais os índios encontravam formas de sobreviver e garantir melhores condições de vida na nova situação em que se encontravam (ALMEIDA, 2003, p. 33-34).

Esta resistência adaptativa pode ser percebida nos aldeamentos indígenas; instituições estas centrais para pensar a relação de subordinação entre colonizador e indígena, pois eram os locais próprios para a execução das propostas de redução e assimilação do nativo. Ao mesmo tempo, eram espaços de resistência, negociação, de efetivar interesses, de aprendizado, experiência e de poder.

Compreende-se que as Coroas Portuguesa e Brasileira percebiam as nações indígenas a partir de uma compreensão dicotomizada entre tupi e tapuia, sendo que os falantes de tupi pela longa convivência com o colonizador eram o parâmetro. Havia dicionários, gramáticas, livros de catequese, orações e músicas em nhenhengatu (MONTEIRO, 2001, p. 43-45), assim como missionários, moradores e militares falantes da língua geral. No litoral os missionários obtiveram certa independência em relação aos interpretes indígenas com a institucionalização de métodos de aprendizagem em Tupi a partir da elaboração de gramáticas e dicionários (BARROS, 1986, p. 07). Mas no centro-oeste dos domínios portugueses a presença de indígenas falantes do tronco macro-jê era massiva, o que fez a presença dos línguas tapuia uma constante na documentação referente aos descimentos, bandeiras, aldeamentos, presídios e escolas voltados aos indígenas em Goiás.

$\mathrm{Na}$ busca de desvelar e dar relevância ao indivíduo indígena e suas relações com o mundo, estrutura-se a pesquisa e consequentemente esse texto a partir de uma leitura da metodologia micro-histórica 
THIAGO CANCELIER DIAS - Contatos e desacatos...

presente no livro Jogos de Escalas: a experiência da microanálise (REVEL, 1998). A obra organizada por Jacques Revel reúne historiadores e antropólogos que discutem o jogo de escalas de análise como ferramenta analítica eficiente para elucidar a história das sociedades ${ }^{2}$. Compreende-se escala como uma faceta do acontecimento histórico, com uma temporalidade, espacialidade e amplitude própria, e com contextos que a compõem. Para Revel, a proposta do jogo de escalas é de "constituir a pluralidade dos contextos que são necessários à compreensão dos comportamentos observados" (REVEL, 1998, p. 27). A ideia do jogo de escalas é elaborar quadros históricos explicativos que vão desde o micro, composto pelas relações interpessoais, até amplitudes variadas, como a das instituições, das posturas políticas, das percepções ambientais, dos hábitos, da linguagem, dos sistemas simbólicos, dos fazeres sociais etc. A meta é complexificar a interpretação sobre acontecimento histórico.

Percebe-se com a variação de escalas de analise a multiplicidade de contextos que possibilitam que indivíduos agenciem ${ }^{3}$ suas relações sociais e modifiquem historicamente a sociedade que os cerca. Cada escala é permeada de contextos, com estruturas um tanto autônomas entre si, mas ao mesmo tempo interligadas. O entendimento micro é contraposto sucessivamente com outros de maior amplitude, considerados por Revel tão pertinentes quanto o micro. A riqueza analítica estaria no cotejo de escalas, não no privilégio de uma escala em relação à outra. A escala micro é formulada a partir do estudo da trajetória de vida de pessoas emblemáticas para a compreensão do acontecimento histórico, em relação com as análises dos contextos que permearam suas ações e discursos.

Giovanni Levi (2000) é um dos marcos na utilização da metodologia micro-histórica em seu livro Herança Imaterial, quando coloca em xeque os modelos analíticos sobre o Antigo Regime, que são

\footnotetext{
${ }^{2}$ Esta perspectiva analítica embasou o mestrado realizado sobre as disputas políticas em torno dos colégios dos jesuítas espanhóis (1845-1855) e italianos (1865-1869), e do colégio Lyceo (1857-1864) ocorridos na Província de Santa Catarina. DIAS, Thiago Cancelier. Questão Religiosa Catarinense: as disputas pelo direito de instruir (1845-1865). Florianópolis: UFSC, 2008.

${ }^{3}$ Quando é dito que pessoas ou grupos agenciam algo, não se está querendo passar a falsa percepção de que os agentes sociais são claros e agem e discursam como sujeitos centrados em si, cônscios de seus atos. Mas sim que são feitas escolhas a partir das experiências pessoais, que efetivamente mudam o mundo em menor ou maior escala, e que deixam indícios capazes de serem analisados e interpretados (DIAS, 2008, p. 17).
}

Espaço Ameríndio, Porto Alegre, v. 7, n. 2, p. 205-226, jul./dez. 2013. 
THIAGO CANCELIER DIAS - Contatos e desacatos...

compostos a partir de parâmetros de uma sociedade com pouca mobilidade. Ele demonstrou que as estratégias individuais e familiares tornavam a sociedade mais estratificada do que o modelo hegemônico poderia compor. Pensa-se que há um modelo analítico relativo à história indígena que desconsidera a sua cultura e agência, que pode ser complexificado no momento que a trajetória de vida de indígenas for contraposta às macroexplicações que na maioria dos casosdesconsideram o indígena como componente ativo.

Mas como estudar a realidade complexa a partir daquilo que não é aparente, que se apresenta no detalhe, ou que só é visível indiretamente nos sintomas daquilo que o produz? Propõe-se dialogar a partir de uma leitura sobre método indiciário proposto por Carlo Guizburg, o "método interpretativo centrado em resíduos, sobre os dados marginais, considerados reveladores" (GINZBURG, 1990, p 149). Esse método parte de pistas para investigar aquilo que não é acessível, de sintomas para analisar a sistemática social que não está aparente e não é reproduzível, que se apresenta a partir de indícios mínimos e que pode levar a interrogar elementos reveladores de fenômenos mais gerais (GINZBURG, 1990, p. 178). Esta metodologia compõe a investigação que se apresenta no texto que segue. Parte-se da leitura de documentos históricos para fornecer compreensões de quem eram as pessoas chamadas de língua nos documentos históricos, e qual a sua atuação diante da expansão da fronteira colonizadora, fornecendo um panorama sobre sua formação, atuação e vivências. São interrogados três contextos, dois relativos ao aldeamento de Mossâmedes, enquanto o último em relação à existência do Colégio de Línguas Princesa Imperial Dona Isabel (1870-1889). Em conjunto, são traçados fragmentos da trajetória de vida de alguns indígenas.

\section{O intérprete indígena}

Maria de Barros (1986) trata a questão do interprete a partir da compreensão que havia uma política indigenista colonial com características supraétnicas, ou seja, a aplicação de um modelo único a toda população indígena em alteridade aos portugueses. Essa política

Espaço Ameríndio, Porto Alegre, v. 7, n. 2, p. 205-226, jul./dez. 2013. 
THIAGO CANCELIER DIAS - Contatos e desacatos...

consistia em formar falantes missionários e indígenas tapuias de nhenhengatu (língua geral) para fazer a interlocução entre colonizadores e as nações indígenas. Concorda-se que havia um modelo único para todos os indígenas, mas mais formado pela incapacidade dos agentes coloniais em compreender as línguas "tapuias", do que pela incapacidade de perceber sua existência. Acredita-se que o modelo era dicotomizado entre tupi e tapuia, sendo que os falantes de tupi pela longa convivência com o colonizador no litoral eram o parâmetro.

Foram elaborados dicionários, gramáticas, livros de catequese, orações e músicas em nheengatu (MONTEIRO, 2001, p. 43-45)4, assim como surgiram missionários, moradores e militares falantes da língua geral a partir de meados do século XVI. No litoral, os missionários obtiveram certa independência em relação aos intérpretes indígenas com a institucionalização de métodos de aprendizagem em tupi, a partir da elaboração de gramáticas e dicionários (BARROS, 1986, p. 07). Este modelo de interlocução construído a partir do nheengatu fornecia subsídios para a lida com as etnias indígenas do litoral; mas com a expansão das fronteiras coloniais o embate com os Tapuia foi inevitável ${ }^{5}$, e 0 arcabouço linguístico historicamente adquirido e construído pelos colonizadores a partir do tupi não se adequava ao contato. Possivelmente o primeiro grupo Tapuia a ter sua fala analisada por missionários e traduzida em catecismos foram os Kiriri (1698), moradores do vale do Rio São Francisco (MONTEIRO, 2001, p. 47-49). A maioria das etnias de Goiás não possuía até meados do século XX mais do que alguns palavras transcritas em textos de cronistas e viajantes naturalistas. Esse desconhecimento das línguas Macro-Jê e Jê pelos colonizadores, e a pluralidade delas, fez com que a figura do língua como interlocutor bilíngue fosse decisiva para as situações de fronteira no século XVIII e XIX. Maria Barros afirma sobre a questão do intérprete e do missionário:

\footnotetext{
${ }^{4}$ Nheengatu teve sua origem no litoral e é chamada de língua geral, predominou em Capitanias como São Vicente do fim do século XVI até meados do século XVIII.

${ }^{5}$ Sabe-se da presença em Goiás (XVIII e XIX) apenas de algumas etnias tupi: Avá (canoeiro), Tapirapé, Guajajara (trazidos do Maranhão) e Carijós (vindo com as bandeiras de São Paulo), a grande maioria eram etnias macro-jê, entre elas: Karajá, Xambioá e Javaé (Iny) - Akroá, Apinajé e Kraô (Timbira) Xerente, Xavante, Xacriabá (Akwén), Kayapó, Bororo (vindos de Cuiabá), Goya, Aráes, Crixás etc.
}

Espaço Ameríndio, Porto Alegre, v. 7, n. 2, p. 205-226, jul./dez. 2013. 
THIAGO CANCELIER DIAS - Contatos e desacatos...

A medida em que os religiosos adquiriam capacidade discursiva em tupi, foi-se restringindo 0 uso do intérprete apenas para casos dos idiomas tapuias. A Provisão sobre a repartição de índios, de 1680 recomendava que os intérpretes tapuias fossem criados em "obediência e sujeição", por serem os referidos índios os "instrumentos de conversão dos gentios" os primeiros contatos com os nativos de língua semelhante à sua para posterior redução às missões (BARROS, 1986, p. 06-07).

Pela dificuldade entre colonizadores e indígenas de se comunicarem, a presença do língua é uma constante na documentação referente aos descimentos, bandeiras, aldeamentos, presídios e escolas voltados aos indígenas. Tem-se a hipótese que o conceito língua, quando representado nas fontes históricas, aparece de duas maneiras: a primeira para denotar toda uma população de indígenas que vivenciaram de alguma forma os aldeamentos, estavam em contato direto com a sociedade colonizadora, eram requisitados como trabalhadores, na maioria batizados, sendo que muitos compreendiam e mesmo falavam o português. Os administradores das coroas portuguesa, e posteriormente brasileira, pensavam os aldeamentos como embriões de futuras vilas formadas por línguas.

Outro sentido encontrado se refere a um individuo específico, indígena, que possui designações e/ou ocupa funções de interlocução nas sociedades não indígena e indígena, e entre as diversas etnias. Esses eram requisitados como intérpretes entre colonizadores e etnias indígenas, geralmente bilíngues, capazes de se comunicarem com a língua materna de sua etnia e com o português, muitas vezes batizados e referendados como cristãos nos documentos. Percebe-se que os línguas geralmente eram aldeados na infância e eram instruídos a terem a colonização como bem maior, sendo inseridos e angariando espaços de atuação diversos nas tramas do sistema escravocrata vigente. Os sertanistas, militares e missionários buscavam adquiri-los por doação, coação, rapto, troca por ferramentas, armas, miçangas e por promessas, comumente eram escolhidos dentre as famílias de estirpe nobre dentro da aldeia indígena. Eram pessoas-chave dentro da hierarquia própria das aldeias indígenas e dos aldeamentos.

Espaço Ameríndio, Porto Alegre, v. 7, n. 2, p. 205-226, jul./dez. 2013. 
THIAGO CANCELIER DIAS - Contatos e desacatos...

Os indígenas recebiam inicialmente uma formação informal para ocupar a função de língua nos aldeamentos, descimentos e bandeiras, inicialmente realizada por sertanistas e missionários (até 1750); após o Diretório dos Índios (1755-1798)6, por administradores e padres; a partir da década de 1850, formalizou-se a instrução dos línguas em colégios nos aldeamentos. Marlene Moura (2006, p. 31) afirma que no total foram fundados em torno de vinte aldeamentos entre a década de 1741 a $1872^{7}$ em Goiás, a maioria de existência curta.

Sabe-se que os sertanistas eram pessoas chaves na expansão e manutenção das fronteiras da coroa portuguesa e brasileira, eles eram requisitados no jogo de interesses entre a coroa, vilas, arraias com os indígenas. Tanto nas bandeiras quanto nos aldeamentos os sertanistas eram geralmente acompanhados por línguas, que faziam intermédio, traduziam, e eram conduzidos a fazer a interlocução entre os mesmos e as comunidades indígenas. Alguns desses línguas foram os responsáveis pelo sucesso das expedições, enquanto outros foram os desarticuladores, e em alguns casos os sabotadores. A bandeira organizada pela comunidade do Arraial de Pilar (1773) é um dos casos onde o língua foi o "tendão de Aquiles" da expedição. No caso, o capitão Maximiano, em sua expedição em terras xavante à procura de metais preciosos, teve a sua vida tirada por um tiro do "índio domesticado" xavante que tinha criado e que era seu guia e tradutor (SILVA e SOUSA, 1872 [1849], p. 456).

Um texto elucidativo é a carta escrita pelo Capitão da Companhia de Dragões, José Pinto da Fonseca, a qual enviou ao General de Goyases; nela é exposta a experiência e a astúcia do alferes na condução da língua na intermediação das excursões militares e descimentos. A língua karajá em questão fazia parte do grupo de oitocentos Karajá e Javaé que foram aldeados juntos na aldeia de Nova Beira (vale do rio Araguaia;

\footnotetext{
${ }^{6}$ O Diretório dos Índios proibia o uso da língua materna nos aldeamentos, prescrevia o batismo e o casamento interétnico, ordenava o uso de roupas e destinava casas nos moldes. Desejava-se que os indígenas estivessem em contato direto com a sociedade colonizadora, fossem trabalhadores, preferencialmente detentores de preceitos cristãos e falantes do português. Diretório que se deve observar nas Povoações dos Índios do Pará, e Maranhão, enquanto Sua Majestade não mandar o contrário. http://www.nacaomestica.org/diretorio dos indios.htm .

${ }^{7}$ Ela os divide em quatro fases: primeira fase (1741-1751 - seis aldeamentos - fundados por sertanistas e missionários), segunda fase (1755-1788 - seis aldeamentos fundados a partir das normas do Diretório dos Índios), terceira fase (1824 - dois aldeamentos) e quarta (1841-1872 - seis aldeamentos) (MOURA, 2006, p. $33-34)$.
}

Espaço Ameríndio, Porto Alegre, v. 7, n. 2, p. 205-226, jul./dez. 2013. 
THIAGO CANCELIER DIAS - Contatos e desacatos...

1773-74) e que foram transferidos para o aldeamento de Mossâmedes (1781) (RAVAGNANI, 1986/1987, p. 124), e que após isso as "epidemias e a disciplina que lhes tentou impor a guarnição encarregada de vigiálos rapidamente dispersaram os aldeados" (TORAL, 1992, p. 38). Apesar de boa parte dos Karajá e Javaé terem se "dispersado" do aldeamento de Mossâmedes nos primeiros anos, há presença aproximadamente vinte anos depois de uma língua karajá advinda de Mossâmedes na bandeira do capitão José Pinto da Fonseca, ocupando a função de intérprete militar.

A carta escrita em primeira pessoa pelo militar detalha informações sobre bandeiras anteriores enviadas à llha do Bananal, inclusive a que a língua karajá em questão foi aldeada, momento em que começou seu aprendizado em "conhecer o cativeiro" através do coronel Antonio Pires do Campo. Afirma ele que o coronel tratou os Karajá com cordialidade nos primeiros dias, depois mataram e aprisionaram muitos indígenas que estavam em uma das aldeias. $O$ sertanista

\begin{abstract}
apanhou muitos prisioneiros, que conduziu nas correntes para seus cativos, sendo a língua que trazemos um da dita presa; passou a crueldade deste homem a mandar pelo caminho amarra estes prisioneiros em árvores, fazendo dar-lhe por divertimento muitos açoites, dizendo que era para os fazer conhecer cativeiro (..) Pelas fazendas do sertão trocou muita d'esta gente por gado e cavalos, e a maior parte fugiu para a sua pátria, publicando nela a tirania dos brancos [grifo meu] (FONSECA, 1867 [1846], p. 378).
\end{abstract}

A negociação era constante: o capitão português doou ferramentas e utensílios, foi conduzido pelas mãos até as esteiras e fumou junto ao maiorals. Ele tinha um trunfo que era ter uma indígena versada na língua inyrybe ${ }^{9}$ e em português. Ele encaminhou a língua a reencontrar seus parentes e quando ocorreu o encontro começaram a chorar os parentes mortos. O militar estrategicamente a deixou dois

\footnotetext{
${ }^{8}$ Maioral - autoridade indígena de uma aldeia, percebe-se que geralmente seu poder está relacionado à força de sua rede de parentesco.

${ }^{9}$ Língua inyrybe é falada por três etnias Iny que vivem no vale do Araguaia: Karajá, Javaé e Karajá Xambioá.
}

Espaço Ameríndio, Porto Alegre, v. 7, n. 2, p. 205-226, jul./dez. 2013. 
THIAGO CANCELIER DIAS - Contatos e desacatos...

dias com os parentes, segundo ele para que ela reforçasse o conhecimento da língua. A partir desse momento ele começa a utilizar a língua para estabelecer a negociação. Certamente os dois dias com os parentes foram o bastante para eles recordassem a matança e o rapto ocorridos há mais de vinte anos, e pensar juntamente com a comunidade como proceder com a excursão militar do alferes. Por outro lado, o militar conduzia com astúcia e com encenação as negociações; ele aproveitou que a língua não se adaptou à comida dos Karajá (segundo ele) e mandou que os escravos servissem-na os escravos a servir com todas as pompas possíveis, e disse para ela dizer que é assim que os brancos tratam os indígenas (o jantar foi assistido por vários indígenas). No outro dia chegaram cinco canoas com parentes da língua e, segundo ele, esfregaram as mãos no seu rosto em sinal de amizade (FONSECA, 1867 [1846], p. 379).

A tática era usar a língua para convencer da boa fé da guarda portuguesa, visto os Karajá estarem com medo de traição. Medo que ficou explicitado quando o maioral estava na tenda dos militares e se assustou com as chaves de um baú; com medo que estivessem pegando correntes para aprisioná-lo, fugiu com todos os indígenas, esvaziou a aldeia. Os militares resolveram ficar no mesmo lugar (FONSECA, 1867 [1846], p. 380). Após três dias surgiu um indígena bororo escravo do maioral, e disse que fugiram "porque queríamos amarrar seu senhor para o levarmos por nosso escravo" (FONSECA, 1867 [1846], p. 380). Afirmou ao escravo que se quisessem fazer mal fariam igual aos outros brancos, quando os indígenas vissem já estariam dentro da aldeia. E que eles atiraram fogos para que eles viessem recebê-los. Em sinal de negociação, ele deu a ferramenta que acreditava ser a mais estimada pelos Karajá, um enxó de fazer canoas, além dessa deu mais algumas ferramentas ao Bororo (FONSECA, 1867 [1846], p. 380).

Neste momento, a negociação ganha outro tom, e o interesse dos Karajá fica mais explícito. O maioral voltou dizendo que seu coração e os mais velhos sabem que os portugueses não querem fazer mal. 0 capitão afirmou que tempos de barbaridades já tinham passado, que os brancos não capturam mais indígenas, e disse que eles poderiam fazer perguntas à língua. Argumentou o bandeirante que se os indígenas se aliassem à coroa viveriam em liberdade e seriam

Espaço Ameríndio, Porto Alegre, v. 7, n. 2, p. 205-226, jul./dez. 2013. 
THIAGO CANCELIER DIAS - Contatos e desacatos...

vassalos do rei (..) que ama e estima como seus portugueses (..) que viam já as utilidades que tiravam de nossa amizade nas ferramentas que possuíam (..) que refletissem que não eram senhores de colherem suas roças com as invasões dos Acroâ, pela qual causa passavam muitas fomes, e que só a sombra de nossas armas podiam Ihes colher e semear seu alvo, e terem seguras suas mulheres na aldeia (..) não poderiam eles conseguir tantas vantagens sem serem aliados dos portuguezes (FONSECA, 1867 [1846], p. 381-382).

O capitão utilizou da música e da distribuição de brindes para promover espaços de convivência e aproximar os indígenas e ganhar confiança. Ele procurou adular as mulheres e para isso utilizou o fato da língua ser mulher e a aproximou das filhas e da irmã do maioral. Ele deu vestidos às filhas do maioral e elas influenciaram a vinda das outras mulheres atrás de brindes, como os brincos e espelhos. A irmã do maioral chorava por ter seu filho raptado por Antonio Pires, o capitão disse que ele era seu filho, que não tinha mãe e que assumiria o lugar do rapaz perdido. Além de toda essa adulação e encenação, tratou um indígena que foi mordido por uma piranha com remédios (FONSECA, 1867 [1846], p. 383).

Os aliados javaé foram comunicados e com isso apareceram no pátio da aldeia karajá, anunciando sua chegada com buzinas e gritaria, e "se meteram também em batalha pegando na frente dos Karajá, avançando e recuando três vezes um batalhão conta o outro" (FONSECA, 1867 [1846], p. 384), sendo que lutas entre guerreiros das duas etnias faziam parte do cortejo, ao mesmo tempo que representavam a força das aldeias. Os Karajá e Javaé estavam em guerra contra os Akwén (Xavante), que saqueavam suas plantações em tempo de seca, matavam os homens, roubavam crianças e mulheres. Como um dos argumentos para a aliança estava o inimigo comum entre as etnias e a coroa. Os maiorais dos Karajá e dos Javaé "assinaram" os termos de vassalagem.

A língua karajá passou por um processo de subordinação, que era instituído a partir do sistema de coação e violência, mas também de favores e adulação. Processo que fica mais claro quando à luz de outro caso de língua formada no mesmo aldeamento de Mossâmedes, a da Kayapó Damiana da Cunha. Os Kayapó ocupavam uma região central 
THIAGO CANCELIER DIAS - Contatos e desacatos...

para os planos expansionistas portugueses, que era a antiga região sul de Goiás ${ }^{10}$, local que era cortado pela via oficial entre São Paulo e Vila Boa de Goiás, resultando no maior contato com a sociedade colonizadora por estarem no caminho do ouro. Em busca do apaziguamento dos conflitos e submissão dos indígenas, a coroa tomou duas iniciativas: enviar jesuítas para promover a pacificação a partir da catequese, introduzindo-os nas aldeias (SILVA e SOUZA, 1872 [1849], p. 441); e realizar devassa sobre alguns sertanistas que praticaram atrocidades com os Kayapó, no intuito de coibir a violência (SILVA e SOUZA, 1872 [1849], p. 442). Mas não bastou e em 1744 foi declarada oficialmente guerra contra os Kayapó e Acroá (SILVA e SOUZA, 1872 [1849], p. 442).

O cronista Silva e Souza definiu a bandeira que "pacificou" e aldeou os primeiros Kayapó como a que obteve melhor êxito, pela sagacidade do pedestre José Luiz. Experiente em batalhas contra os Kayapó, partiu do aldeamento de São José de Mossâmedes com cinquenta homens com armas de fogo: 26 Bororo da Aldeia de Rio das Pedras, 12 Akroá de São José de Mossâmedes e 12 soldados (GIRALDIN, 2000 , p. 166). Junto à tropa foi um língua kayapó chamado Feliciano José Luis, que no momento que encontrou alguns Kayapó, "os afagou e Ihes deu os presentes que levava, persuadindo-os a virem ver o capitão grande que os enviava" (SILVA e SOUZA, 1872 [1849], p. 459-460); com isso, trinta e seis Kayapó foram para o aldeamento de Maria I. Resultando, depois de dois anos, na conquista, segundo Alencastre, de quatro aldeias, conquistadas com uma população de mais de 687 indivíduos, dos quais 328 foram batizados (GIRALDIN, 2000). Esses indígenas foram alocados no aldeamento de Maria I e depois encaminhados para Mossâmedes em 1813 (restavam apenas duzentos e sessenta e sete) (RAVAGNANI, 1986/1987, p. 127).

Ravagnani, a partir da leitura dos cronistas Luiz Silva e Souza (padre) e José Alencastre (Presidente da Província), e dos viajantes naturalistas Augustin Saint-Hilaire e Johann Emanuel Pohl, afirma que o aldeamento era administrado nesse período por um comandante e quinze pedestres, que os indígenas eram castigados e levados ao tronco

\footnotetext{
${ }^{10}$ A área que os Kayapó ocupavam corresponde hoje a parte do Triângulo Mineiro, norte de São Paulo e Mato Grosso do Sul e sul de Goiás.
}

Espaço Ameríndio, Porto Alegre, v. 7, n. 2, p. 205-226, jul./dez. 2013. 
THIAGO CANCELIER DIAS - Contatos e desacatos...

pelo capitão, e que "sob a inspeção dos pedestres, os Kayapó cultivavam a terra em comum, trabalhando cinco dias da semana e descansavam dois, no domingo e na quinta-feira, quando caçavam, ou plantavam inhame e batata" (RAVAGNANI, 1986/1987, p. 125). E que o comandante fazia a distribuição da produção, vendia o excedente na cidade e aos pedestres e com o dinheiro da venda o capitão deveria comprar sal, fumo, tecido de algodão, instrumentos de ferro etc. Havia um serralheiro e um carpinteiro, que segundo Ravagni consertavam as ferramentas e os edifícios, uma mulata ensinava as mulheres a fiar, ganhando $50 \$ 000$ por ano. Aponta as constantes fugas como sendo devido ao fato dos pedestres explorarem os indígenas, sendo que os fugitivos eram perseguidos e em alguns casos capturados (RAVAGNANI, 1986/1987).

Provavelmente esse comandante era o sargento de pedestres Manuel Pereira da Cruz, marido da Kayapó e principalll Damiana da Cunha, neta do maioral Angraiochá. Ela realizou descimentos nas aldeias kayapó, buscou os indígenas fugitivos e era respeitada no aldeamento (SAINT-HILAIRE, 1975, p. 72). Ela realizou diversas expedições, em sua maioria no alto Araguaia. Na primeira aldeou setenta Kayapó que estavam na cabeceira do Araguaia (1808), região central em suas andanças. Fez descimentos de centenas de Kayapó em $1819,1821,1827$ a 1831, ano de sua morte (GIRALDIN, 2000, p. 172). Pelo que é possível interpretar das bibliografias e fontes, a decadência de São José dos Mossâmedes tomou forma final em 1831, quando Damiana da Cunha faleceu, após retornar de um descimento. Seu irmão, Manoel da Cunha Menezes, que pelo menos desde 1828 era diretor do aldeamento (população de 128 pessoas) (RAVAGNI, 1986/1987), passou a incentivar a fuga, sendo preso e morrendo por isso, tornando o aldeamento desabitado por Kayapó e inoperante no ano seguinte (GIRALDIN, 2000).

Damiana da Cunha foi aldeada quando criança, ela era filha de um maioral kayapó e junto ao seu irmão foram batizados pelo governador Luiz da Cunha de Menezes, recebendo seu nome de família. A escolha

\footnotetext{
${ }^{11}$ Ser língua possibilitava outras áreas de atuação, como ocupar o cargo de índio principal. Compreendese que os principais tiveram sua atuação "principalmente direcionada e circunscrita ao âmbito policial e de repartição do trabalho, esferas de competências, aliás, que reorientavam, em diversos sentidos, a sua representatividade dentro do contexto indígena" (CARVALHO, 2008, p. 515).
}

Espaço Ameríndio, Porto Alegre, v. 7, n. 2, p. 205-226, jul./dez. 2013. 
THIAGO CANCELIER DIAS - Contatos e desacatos...

de crianças filhas do maioral para serem batizadas pelo governador era parte dos procedimentos para encaminhá-las para serem línguas. Essas crianças possuíam um locus de anunciação de lideranças por serem de famílias indígenas de estirpe nobre, e por serem batizadas por autoridades coloniais, fazendo possivelmente soar entre os indígenas como um duplo pertencimento a famílias poderosas. Provavelmente a força de Damiana estivesse na fraqueza dos aldeamentos, que era a incapacidade de se reproduzir biologicamente, necessitando recorrentes descimentos de indígena dos sertões (CUNHA, 1998, p. 13). Como dito por Manuela Carneiro da Cunha, a reprodução dos aldeamentos era predatória, "índios das aldeias eram compulsoriamente alistados nas tropas de resgates para descer dos sertões novas levas de índios que continuamente vinham preencher as lacunas deixadas por seus predecessores" (CUNHA, 1998, p. 13). A reprodução predatória exigia línguas, que partiam do prestígio enquanto elite indígena para garantir "poder diante dos colonizadores e poder político e espiritual diante do seu grupo étnico" (APOLINARIO, 2005, p. 105), alinhando-se à "ordem colonial como estratégias de manterem sua influência e poder e para obter uma tolerância, mesmo que mínima dos colonizadores" (APOLINARIO, 2005, p. 105). Indígenas esses que ocupavam cargos destinados a eles pelos colonizadores, o que "era uma prática com intuito tutelar e uma forma de integrá-los ao sistema colonial" (APOLINARIO, 2005, p. 105).

Os línguas eram intérpretes militares que ocupavam espaços de poder dentro da hierarquia quanto a lida com indígenas, seja como capitães mores, principais ou intérpretes militares. Faziam parte de um sistema que mudou com o Diretório dos Índios. Momento no qual se passou, em parte, da vontade, nas palavras da época, de "desinfestar" os indígenas para o interesse em torná-los vassalos, conduzi-los à cristandade e assimilá-los como meio de garantir a posse das terras, principalmente em relação à Espanha, e a todo conflito em torno do Tratado de Madri. A partir desse tratado, ter uma população cristã e falante de português era garantia jurídica de manutenção da terra diante do crescente acirramento de conflito com a Espanha no século XVIII.

Essa situação muda com a Independência do Brasil e consequente alteração de política de Estado quanto a indígenas ocasionada. O 
THIAGO CANCELIER DIAS - Contatos e desacatos...

objetivo passa a ser tomar as terras dos indígenas e assimilá-los como mão de obra, ao invés da política de torná-los vassalos para garantir territórios em disputa. Em meados do século XIX, os aldeamentos passam a ter escolas para cristianizar, formar línguas e trabalhadores no geral, fato que é o cerne da discussão que segue.

\section{Colégio de Línguas Princesa Imperial Dona Isabel (1870-1889)}

Sabe-se que a política de assimilação com a utilização e formação de línguas teve outras nuances a partir de meados do século XIX; foi reformulada com a edificação dos primeiros colégios, nos quais partiam da catequese, do ensino de português, do lido no trabalho e convívio com moradores não indígenas para formar, também, interlocutores. Marta Amoroso (1998) afirma que a partir de 1845 o indigenismo brasileiro passa por uma fase de identificação com a missão católica, com a coroa subvencionando a vida de capuchinhos que vão estar presentes em quase todos os aldeamentos do Brasil. O Diretório tinha força de Lei até 1798. Apesar de extinto, e no vácuo legal que se instalou, teve capacidade normativa nos aldeamentos e no relacionamento com as populações indígenas até 1845 . Momento que é publicado o Regulamento da catequese e civilização dos índios, que versava que a conversão, educação e assimilação branda da população indígena deveria ser realizada por missionários nas colônias militares, presídios e aldeamentos com a instrumentalização de escolas (AMOROSO, 1998, p. 1-3). Os capuchinhos estabeleceram missão em Goiás a partir da década de 1840, sendo que com o Decreto de 1857 a supervisão dos aldeamentos passa para os religiosos ${ }^{12}$. Em 1859, há o estabelecimento das primeiras escolas primárias nos aldeamentos e presídios conduzidos por eles (AMOROSO, 1998, p. 1-3).

\footnotetext{
${ }^{12}$ Estabelecimento de missões realizadas por capuchinhos em Goiás (séc. XIX): Missões de São Vicente de Boa Vista (1841), São Joaquim (ou São José) do Jamimbu (1845), Santa Maria do Araguaia (1845), São Pedro Afonso (1849), Teresa Cristina (Piabanhas - 1851) e Missão dos Xambioá (1872). Havia aldeias antigas como a de Graciosa (1824 - década de 1850), Carolina e Pedro III em Carretão (1764 final do séc. XIX) (KARASH, 2009, p. 404).
}

Espaço Ameríndio, Porto Alegre, v. 7, n. 2, p. 205-226, jul./dez. 2013. 
THIAGO CANCELIER DIAS - Contatos e desacatos...

Em 1870 foi fundado o Colégio de Línguas Princesa Imperial Dona Isabel (1870-1889)13 em Leopoldina, onde hoje é Aruanã (vale do rio Araguaia). Couto Magalhães é o idealizador desse colégio, ele parte das experiências jesuíticas espanholas nos Sete Povos das Missões (Rio Grande do Sul) e das prerrogativas da Lei de 1845, que deliberava a criação de "oficinas de artes mecânicas, pregava o estímulo à agricultura, o treinamento militar e o alistamento dos índios em companhias especiais, como as de navegação" (AMOROSO, 1998, p. 03). A lei apregoava também a catequese e ensino de português e matemática.

O Colégio Isabel foi fundado por um grupo que em certa maneira retomou "a velha ideia jesuítica de catequizar os índios em suas próprias línguas (..) as pessoas mais indicadas para levar o cristianismo ao mato eram, 'os filhos das famílias aborígines, educados desde a infância nas ideias, costumes e instituições de nossa sociedade"” (KARASH, 2009, p. 405). Segundo o documento que regia o colégio, intitulado Instruções para Organização, Direção e Regime Econômico do Colégio Isabel, havia interesse que os indígenas interlocutores mantivessem sua língua materna, além de aprenderem o português (MARIN, 2009, p. 155). Essa política linguística indicava que os professores não indígenas "tivessem um mínimo de conhecimento da língua usada pela mais numerosa etnia da região, de modo a permitir a interlocução entre os professores e os indígenas" (MARIN, 2009, p. 156).

O colégio funcionava em sistema de internato, no qual era realizado também o ensino religioso. No documento consta que no colégio deveria haver ensino de primeiras letras, português, matemática, além de ensino profissionalizante. Em um primeiro momento se desejava uma dupla formação: formar intérpretes (língua) e profissionais voltados à navegação do Araguaia. Os meninos seriam formados como marinheiros, para tanto deveriam aprender o ofício de ferreiro, carpinteiro e mecânico, aplicado à construção naval. Também a eles era desejado que se ensinasse práticas agrícolas. Quanto às meninas, deveriam aprender a lida doméstica, especialmente cozinhar, costurar,

\footnotetext{
${ }^{13} \mathrm{Na}$ década de 1870 funcionavam cinco colégios em aldeamentos em Goiás. Além do Colégio Isabel havia outros conduzidos por missionários capuchinhos italianos nos aldeamentos de São José do Araguaia, Xambioás, Santa Maria e Piabanha (KARASH, 2009, p.406).
}

Espaço Ameríndio, Porto Alegre, v. 7, n. 2, p. 205-226, jul./dez. 2013. 
THIAGO CANCELIER DIAS - Contatos e desacatos...

fiar e tecer algodão (MARIN, 2009). Com o intuito de ensinar a navegação e manejo de máquinas a vapor, o governo contratou por um período de três anos o engenheiro inglês Alexander MacGregor Wilkes, para ensinar desenho linear e mecânica. Devido à dificuldade de comunicação, o fato de não haver a possibilidade de aulas práticas, e as crianças não compreenderem os desenhos, ele não ficou até o fim do contrato (MARIN, 2009, p. 158). Após cinco anos de funcionamento, o colégio recebeu um novo direcionamento, estava evidente que o objetivo de formar "bons marinheiros, mecânicos, carpinteiros e ferreiros não haviam sido alcançados" (MARIN, 2009, p. 158). Couto de Magalhães direcionou o ensino do Colégio Isabel para o ensino da criação de gado, mantendo o desejo pela formação de línguas (MARIN, 2009).

A violência com relação às crianças já iniciava no seu modo de recrutamento para o colégio, nos primeiros anos há casos de pais que levaram seus filhos para ficarem no internato por livre escolha, mas o principal método era o rapto (MARIN, 2009, p. 159) e a troca de ferramentas, fumo, roupas, armas etc por crianças, geralmente frutos de rapto nas guerras entre as etnias. O governo provincial incentivava o tráfico de crianças quando as trocava com os indígenas e quando as comprava de moradores. Os principais pontos de comércio de crianças eram as fortalezas e presídios, que tinham a função, também, de "negociar as crianças para, depois, enviá-las ao Colégio Isabel" (MARIN, 2009, p. 160). Marin cita Ehrenreich, que descreve a situação de violência (1888):

O diretor tratava os índios como escravos, mandandoos trabalhar para ele. Desamparados, eles estavam entregues às brutalidades dele e dos amigos dele. As moças estavam à mercê dos instintos de todos esses opressores. A maioria delas já havia dado à luz o filho ou aguardava o momento. Havia muito tempo que não chegavam índios novos, pois as violências dos civilizados brancos afugentavam os selvagens cada vez mais (MARIN, 2009, p. 159).

Após serem retiradas das aldeias, as crianças adentravam em um sistema impositivo, que as obrigava a serem batizadas e terem seus 
THIAGO CANCELIER DIAS - Contatos e desacatos...

nomes mudados, usar uniformes ${ }^{14}$, consumir alimentação ocidental ${ }^{15}$, trabalhar na criação e domesticação de gado, porco e galinha, usar medicação e métodos de cura ocidentais, além de serem estimulados ao comércio. Além disso, deveriam conviver com não indígenas, como parte dos esforços de serem civilizados. Crianças não indígenas passaram a serem matriculadas em 1879 , no bojo de ensiná-las a ler, escrever, trabalhar nas oficinas e aprender a falar línguas indígenas na interação com os indígenas. O conhecimento das línguas indígenas e a instrução religiosa, segundo os governantes, "poderiam formar catequistas instruídos na relação com os indígenas, no conhecimento de seus hábitos" (MARIN, 2009, p. 157), Em 1881, encontravam-se matriculadas nove crianças nacionais (MARIN, 2009, p. 158).

Marin faz uma análise da trajetória de alguns egressos do colégio e percebe que alguns alunos encaminharam, em certa medida, suas vidas a partir da experiência de estarem internados no colégio. Um dos objetivos da instituição era formar intérpretes; sabe-se da existência de ao menos um, chamado Uadjurema (Kayapó), que em 1875 fora designado intérprete na Colônia Chambioá, morrendo dois anos depois (MARIN, 2009, p. 162). Afirma que alguns Karajá trocavam madeira por ferramentas e utensílios com os navios a vapor, e que um deles era um ex-aluno que "se especializou em navegação a vapor e vendia lenha e trabalhava em navios por dinheiro" (MARIN, 2009, p. 164), enquanto outros trabalhavam como vaqueiros nas fazendas vizinhas. Aponta que dois ex-alunos karajá assumiram papéis de liderança em suas aldeias, enquanto dois outros alunos kayapó se tornaram líderes e adotaram um estilo aguerrido no trato com o Karajá e fazendeiros vizinhos a sua aldeia (MARIN, 2009, p. 162).

O Presidente de Província Couto Magalhães, além de idealizador do colégio, foi propositor, seis anos depois, de um "método de ensino de línguas" em lendas tupi para o ensino de nheengatu no livro $O$

\footnotetext{
${ }^{14}$ Uniformes usados à "moda da população branca, algumas com tecidos ou ornamentos importados: calças e camisas de brim nas cores brancas e azuis, paletós de alpaca preta fina, ceroulas tipo americano, gravatas pretas, chapéu de pelo de lebre, lenços brancos bordados, xales, meias para as índias, lenços para o cabelo, baetas encorpadas, chinelos de couro e sapatos pretos.Os tecidos mais usados eram o morim, riscado grosso e a chita, normalmente colorida e floreada" (MARIN, 2009, p. 156).

15 "Dentre os produtos adquiridos para a alimentação, incluíam-se: arroz pilado, feijão, carne de gado, toucinho, milho para canjica, farinha de mandioca, farinha de milho, sal, café, açúcar e rapadura. Da lista de medicamentos, constavam vacinas e produtos para curativos" (MARIN, 2009, p. 156).
}

Espaço Ameríndio, Porto Alegre, v. 7, n. 2, p. 205-226, jul./dez. 2013. 
THIAGO CANCELIER DIAS - Contatos e desacatos...

Selvagem. No livro há apontamentos sobre a "domesticação do selvagem", o usufruto de sua mão de obra e de suas terras (COUTO MAGALHÃES, 1876, p. VIII). O livro apresenta informações que trazem indicativos dos preceitos que levaram o presidente a criar um colégio para indígenas e um livro com fins didáticos, como quando em seu discurso faz o cálculo que é possível conquistar "um milhão de braços aclimatados" (COUTO MAGALHÃES, 1876, p. VIII), a partir da constituição de um corpo de intérpretes militares. Seu método se baseia nas obras do jesuíta Antonio Ruiz de Montoya (1585 - 1652). O general elabora um método que partia de mitos tupi para ensinar nheengatu, como base para ensinar português a povos indígenas do sertão, sendo que a maioria dos alunos do colégio eram tapuia, ou seja, falantes de línguas do tronco Macro-Jê. Essa aparente incongruência é explicada por ele pela argumentação de que mesmo os Tapuia não falando a mesma língua (tupi), ela é entendida, por ser uma língua difundida (COUTO MAGALHÃES, 1876, p. VIII).

Continuando sua explanação na apresentação de seu livro, Couto Magalhães afirma que o padre Montoya dizia o seguinte, no contexto de um dos colégios para indígenas no Paraguai no qual trabalhava: "aquela tribo onde houver um língua é uma tribo mansa" (COUTO MAGALHÃES, 1876 , p. XI). Couto Magalhães considerava vital para domesticar os selvagens fazer com que eles entendessem o português, pois a partir de sua compreensão da teoria de perfectibilidade humana ${ }^{16}$ os indígenas, quando aprendessem o português, tenderiam quase que naturalmente a se civilizar (COUTO MAGALHÃES, 1879, p. XXXII). Seu projeto tinha como principal prerrogativa a assimilação linguística como caminho para a assimilação total dos indígenas. Este modelo de colégio foi levado ao Rio Doce e ao Amazonas (CUNHA, 1998, p. 139-140).

\section{Considerações finais}

\footnotetext{
${ }^{16}$ É uma teoria elaborada no século XVIII, na qual os povos selvagens são entendidos e caracterizados como primitivos. Primitivos pela compreensão de que foram os primeiros a aparecer na terra de nossa espécie, e como tal na evolução estariam mais distantes no caminho único como espécie a uma possível "perfectibilidade" (SCHWARCZ, 1993, p. 44).
}

Espaço Ameríndio, Porto Alegre, v. 7, n. 2, p. 205-226, jul./dez. 2013. 
THIAGO CANCELIER DIAS - Contatos e desacatos...

Partindo do proposto, se constata que, com as reformas pombalinas, a formação dos línguas passou a ser estruturada, em Goiás, a partir das prerrogativas que os percebiam como parte da solução quanto aos conflitos em relação às nações indígenas, à falta de mão de obra e à manutenção e expansão dos territórios portugueses em relação as nações indígenas e coroas europeias, em especial os Espanhóis. Com os aldeamentos normalizados pelo Diretório dos Índios, a formação dos línguas passou a ser institucionalizada e fomentada como meio para levar a cristandade e civilidade aos indígenas, com o desejo de tornar as nações indígenas vassalas da coroa portuguesa, legalizando assim as terras que se localizavam fora dos domínios portugueses, terras outorgadas pelo Tratado de Madri como pertencentes à Espanha. A partir de meados do século XIX, os línguas passaram a ser formados em colégios localizados em aldeamentos e missões religiosas, e em aldeamentos administrados diretamente pela coroa. O viés da coroa brasileira passou a ser o de desocupar as terras de indígenas para a formação de fazendas e outros empreendimentos dos colonizadores, ocupar o território e formar trabalhadores, dependendo, assim, de interlocutores indígenas.

\section{Referências bibliográficas}

ALMEIDA, Maria Regina C. Metamorfoses indígenas: identidade e cultura nas aldeias coloniais do Rio de Janeiro. Rio de Janeiro: Arquivo Nacional, 2003.

AMOROSO, Marta Rosa. Mudança de hábito: catequese e educação para índios nos aldeamentos capuchinhos. Revista Brasileira Ciências Sociais, São Paulo, v. 13, n. 37 , p. 101-114, jun. 1998.

APOLINÁRIO, Juciene Ricarte. Os Akroá e outros povos indígenas nas Fronteiras do Sertão: as práticas das políticas indígena e indigenista no norte da Capitania de Goiás - século XVIII. 2005. 269f. Tese (Doutorado em História) - Universidade Federal de Pernambuco, Recife, 2005.

BARROS, Maria Cândida D. M. Um caso de política linguística: a questão do intérprete e do discurso religioso no Brasil colonial. Amerindia, Paris, n. 11, p. 69-78, 1986.

Espaço Ameríndio, Porto Alegre, v. 7, n. 2, p. 205-226, jul./dez. 2013. 
THIAGO CANCELIER DIAS - Contatos e desacatos...

CARVALHO, Valéria. Autoridade Brasil Indígena e Legislação Indigenista no Brasil. História Revista, Goiânia, v. 13, n. 2, p. 511-540, jul./dez. 2008.

COUTO MAGAlHÃES, José Vieira. O Selvagem: curso de língua geral segundo Ollendorf - Compreendendo o texto original de lendas tupis (parte I) - Origens, Costumes e região selvagem: methodo a empregar para amansa-los por intermédio das colonias militares e do interprete militar. Rio de Janeiro: Tipografia da Reforma, 1876.

CUNHA, Manuela Carneiro. Introdução a uma história indígena. In: (Org). História dos Índios do Brasil. São Paulo: Cia das Letras. 1998.

DIAS, Thiago Cancelier. Questão Religiosa Catarinense: as disputas pelo direito de instruir (1843-1864). 2008. 152 f. Dissertação (Mestrado em História) - Universidade Federal de Santa Catarina, Florianópolis, 2008.

Diretório que se deve observar nas Povoações dos Índios do Pará, e Maranhão, enquanto Sua Majestade não mandar o contrário. Disponível em: http://www.nacaomestica.org/diretorio_dos_indios.htm . Acesso em: 08 jul. 2013.

FONSECA, José Pinto da. Carta que o alferes José Pinto da Fonseca escreveu ao Exmo. General de Goyazes, dando-lhe conta do descobrimento de duas nações de índios, dirigida do sitio onde portou (1846). Revista Trimensal de Historia e Geografia ou Jornal do Instituto Histórico e Geográfico Brasileiro, Rio de Janeiro, v. 8, n. 3, tomo VIII, 1867. Disponível em: http://www.ihgb.org.br/rihgb/rihgb1846t0008c.pdf . Acesso em: 30 dez. 2013.

GINZBURG, Carl. Mitos, emblemas, sinais: Morfologia e História. São Paulo: Companhia das Letras, 1990.

GIRALDIN, Odair. Renascendo das cinzas: um histórico da presença dos Cayapópanara em Goiás e no triângulo mineiro. Sociedade e Cultura, Goiânia, v. 3, n. 1, p. 161-184, jan./dez. 2000.

LEVI, Giovanni. A herança imaterial: trajetória de um exorcista no Piemonte do século XVII. Rio de Janeiro: Civilização Brasileira, 2000.

KARASH, Mary. Catequese e cativeiro: política indigenista em Goiás, 1780-1889. In: CUNHA, Manuela Carneiro da (Org). História dos índios do Brasil. São Paulo: Companhia das Letras, 2009.

MARIN, Joel O. Bevilaqua. A formação de trabalhadores brasileiros: a experiência do Colégio Isabel. História Unisinos, São Leopoldo, v. 13, n. 2, p. 154-167, maio/ago. 2009.

MOURA, Marlene. Aldeamento Carretão: "marco zero" da história das relações interétnicas dos tapuios. Dimensões, Vitória, n. 18, p. 28-48, 2006.

Espaço Ameríndio, Porto Alegre, v. 7, n. 2, p. 205-226, jul./dez. 2013. 
THIAGO CANCELIER DIAS - Contatos e desacatos...

MONTEIRO, John Manuel. Armas e armadilhas: história e resistência dos índios. In: NOVAES, Adauto (Org.). A outra margem do Ocidente. São Paulo: Companhia das letras, 1999.

Tupis, Tapuia e Historiadores: Estudos de História Indígena e do Indigenismo. 2001. 235f. Tese (Concurso de Livre Docência) - Unicamp, Campinas, 2001.

RAVAGNANI, Oswaldo M. A agropecuária e os aldeamentos indígenas goianos. Perspectivas, Araraquara, v.. 9/10, p. 119-143, 1986/1987.

REVEL, Jacques (Org.). Jogos de escalas: A experiência da microanálise. Rio de Janeiro: Fundação Getúlio Vargas, 1998.

SÁEZ, Oscar Calavia. A terceira margem da história: estrutura e relato das sociedades indígenas. Revista Brasileira de Ciências Sociais, São Paulo, v. 20, n. 57, p. 38-52, fev. 2005.

SAINT-HILAIRE, Auguste. Viagem à Província de Goiás. São Paulo: Edusp; Belo Horizonte: Itatiaia, 1975.

SCHWARCZ, Lilia Moritz. O Espetáculo das Raças: cientistas, instituições e questão racial no Brasil 1870-1930. São Paulo: Companhia das Letras, 1993

SILVA E SOUSA, Luiz Antonio da. Memória sobre o descobrimento, governo, população, e cousas mais notáveis da Capitania de Goyaz. Revista Trimensal de Historia e Geographia ou Jornal do Instituto Historico e Geographico Brasileiro, Rio de Janeiro, v. 12, tomo XII, p. 429-510, 1872 [ $4^{\circ}$ trimestre de 1849]. Disponível em: http://www.ihgb.org.br/rihgb/rihgb1849t0012c.pdf . Acesso em: 30 dez. 2013.

TORAL, André. Cosmologia da Sociedade Karajá. 1992. 280 f. Dissertação (Mestrado em Antropologia Social), Universidade Federal do Rio de Janeiro, Rio de Janeiro, 1992.

Espaço Ameríndio, Porto Alegre, v. 7, n. 2, p. 205-226, jul./dez. 2013. 